\title{
REUNIÓES CIENTIFICAS
}

\author{
ASSOCIAÇAO PAULISTA DE MEDICINA \\ SECÇAO DE NEURO-PSIQUIATRIA
}

Sessão ordinária - 5, fevereiro, 1944

PRESIDENTE: DR. PAULO PINTO PUPO

\begin{abstract}
Paraplegia por tumor intradural. Laminectomia. Cura (com apresentação do doente), Dr. J. P. Marcondes de Souza.

O A. relata un caso de paraplegia espasmódica no qual, inicialmente, foi diagnosticado mal de Pott dorsolombar. A radiografia com lipiodol, punção raquidiana e o exanıe do líquido céfalo-raquidiano mostraram sinais de bloqueio raquidiano por tumor. Após laminectomia evidenciou-se um tumor do tamanho de uma uva ao nível da $8 .^{*}$ vértebra dorsal, junto à face posterior da medula, tendo sido fàcilmente separado com espátula. O exame anátomo-patológico diagnosticou un granuloma telangiectásico. O A. chama a atenção para a raridade da localização dêste granuloma, que alguns autores consideram como forma de passagem entre neoplasia e inflamação crônica, e para a sinonímia de botriomicoma, que não deve ser empregada, pela confusão que pode causar com a botriomicose animal. Para terminar, foi apresentado o doente, perfeitamente curado.
\end{abstract}

Neurocirurgia nos Estados Unidos. Dr. A. de Mattos Pimenta.

O A. apresenta as impressões gerais de uma viagem e discute certos problemas neurocirúrgicos de maior atualidade. Descreve sumàriamente a viagem e estadia no Instituto Neurológico de Nova York, onde freqüentou o Serviço de Stookey e T. Putnam, atual diretor. Classifica a organização do Instituto Neurológico como ideal para estudo e tratamento das moléstias nervosas. Relata as visitas aos Institutos de Chicago e Montreal onde trabalham Bailey, Oldeberg, Penfield, e organizados como o de N. York. Da Clínica Mayo trouxe as melhores impressões da organizàção e do nível científico. A seguir descreve o Hospital da Universidade de Michigan, onde fêz estágio, pertencendo ao "staff" neurocirúrgico como assistente do Prof. Max Peet. Chama atenção para a alta padronização dos hospitais americanos e para a caraterística do trabalho em equipe das diversas especialidades. De modo geral, os serviços se dividem em clínica e cirurgia, e dentro desta divisão não há separação das especialidades; apenas os doentes são preferencialmente localizados. Constituem exceção os serviços de tisiologia, o Instituto NeuroPsiquiátrico, a maternidade, a clínica infantil. Elogia o serviço de enfermagem, descreve as finalidades e atividades do serviço social e sua colaboração no seguimento pós-operatório. $O$ arquivo é geral para todo o hospital; uma secção mantém em dia as observações e a classificação do numeroso material científico. Crê que um dos fatores de aproveitamento reside no fato dos 
médicos dedicarem todo o tempo no hospital, internando no mesmo seus doentes particulares.

Após decrever o serviço neurocirúrgico do Dr. Peet e de seus assistentes Kahn, Woods e List, passa a considerar diversos problemas neurocirúrgicos. Considera, em primeiro lugar, a semiologia clínica e os processos paraclínicos, evidenciando particularidades tais como: uso rotineiro da punção lombar com manometria obrigatória; uso do oxigênio para pneumencefalografias e ventriculografias; uso de ar subdural como meio diagnóstico e terapêutico e neste último caso com a mesma significação do pneumotórax em tisiologia, no intúito de evitar aderências cerebromeníngeas. $O$ uso das mielografias gasosas está se intensiffcando, devido a algưns acreditarem na ação irritante do lipiodol como corpo estranho. Relata ainda o incremento, no meio neurocirúrgico, do emprêgo da arteriografia cerebral.

Passa, em seguida, a analisar a diferença clínica e prognóstica dos tumores na idade aduta e na infância. Expõe a situação atual do tratamento cirúrgico dos gliomas. Discute a questão dos tratamentos cirúrgico e radioterápico nos adenomas da hipófise. A respeito dos traumas craniomedulares diz que, graças aos tratamentos de choque e à ação das sulfas, há tendência a intervenções mais precoces e mais amplas; especialmente nos casos de traumas medulares, onde a drenagem contínua da bexiga explica, em grande parte, o sucesso cirúrgico.

Relata o interêsse de certas clínicas no problema do hidrocéfalo, as diversas operações preconizadas, embora não tivesse voltado entusiasmado com os resultados observados. Descreve as operações de secção do piramidal, da alça lenticular e descorticação, como métodos de tratamento do difícil problema do tremor parkinsoniano.

A respeito do problema da dor, comenta as neuralgias do trigêmeo, nas quais a ressecção seletiva retrogasseriana é a rotina. A cordotomia é de indicação freqüente, havendo ainda trabalhos interessantes a respeito da sistematização do feixe espinhotalâmico.

Assunto de todos os dias nas clínicas neurocirúrgicas norte-americanas é a hérnia do núcleo pulposo. Todos casos de ciática crônica, após estudos sistematizados, são encaminhados à laminectomia exploradora, e são tais os resultados obtidos, que os cirurgióes prescindem cada vez mais do emprêgo da mielografia. Processo terapêutico bem difundido é a leucotomia e a lobotomia de Muniz, porém nada há de novo a respeito de sua explicação terapêutica. A cirurgia da hipertensão arterial ainda se acha na fase de discussão e experimentação, tendo evoluído graças aos estudos de Peet, os quais permitem, nos casos bem indicados, um bom prognóstico.

\section{Sessão ordinária - 6, março, 1944}

Semiologia endócrina da hipófise. Métodos e interpretações. Prof. J. Ignácio Lobo. (conferência).

Para exame das alterações funcionais da hipófise anterior, utilizam-se alguns métodos, os mais importantes dos quais são os seguintes: algumas medidas antropométricas, exame radiológico de algumas articulações para verificação de núcleos de ossificação e cartilagens epifisárias, exame especializado da genitália externa e interna, determinação biológica de hormônios hipofisários, medida do metabolismo basal e teste terapêutico. Conforme a função a ser avaliada, varia a escolha dêsses métodos. 
As insuficiências da função somatotrópica são apreciadas através da medida da estatura e dos diâmetros vertexpúbis e pubicoplantar. Uma estatura extremamente reduzida já é um indicio de que o nanismo é de origem endócrina, mas não basta de per si para garantir a natureza hipofisária da deficiência. Nem mesmo a conservação das proporções segmentares confirma a suspeita. Só o emprêgo dos outros métodos poderá esclarecer o caso: assim, por exemplo, o exame radiológico da articulação do punho mostrará que a ossificação está normal ou levemente atrazada e se o paciente já tiver idade superior a 20 anos, ver-se-á que as epífises se conservam abertas. A genitália é sempre muito reduzida, do tipo infantil, pois o nanismo hipofisário se acompanha sempre de insuficiência da função gonadotrópica da hipófise. O nível mental é normal. A resposta ao tratamento hormonal específico é muito ingrata por não se dispor de preparações ativas. Estes dados diferenciam o nanismo hipofisário: $1^{\circ}$ ) do nanismo tireóideo, em que a idade óssea é sempre muito mais atrasada, atraso èste mais acentuado do que o correspondente atraso do crescimento; em que, além disso, existe grande baixa do nível mental e a resposta ao tratamento hormonal é satisfatória pelo menos para o "déficit somático; $2 .^{\circ}$ ) do nanismo distrófico, em que a curva do crescimento e a evolução da genitália são sempre melhores; $\left.3 .^{\circ}\right)$ do nanismo gonadal, em que o desenvolvimento da genitália até é precoce $; 4 .^{\circ}$ ) do nanismo acondroplástico, em que o comprimento do tronco é normal, ao passo que o dos membros é muito reduzido.

Um exagêro da função somatotrópica acarreta, durante o período de crescimento, um gigantismo longitudial que se diferencia do gigantismo eunucóide porque neste a genitália não se desenvloveu, e a medida púbicoplantar se apresenta muito avantajada. A hiperfunção somatotrópica quando ocorre depois que as epífises ósseas estão soldadas, acarreta o conhecido quadro da acromegalia, no qual se encontra, além do crescimento das extremidades, proliferaçốes ósseas justa-articulares demonstráveis pelo exame radiográfico: nesta afecção é freqünte o aparecimento de hiperglicemia e, às vezes, até de verdadeiro diabete ocasionado por um excesso de hormónio diabetógeno, secretado pelas mesmas células eosinófilas da hipófise anterior. Até o presente uão foi possível demonstrar, em ensaios biológicos, a presença de um excesso de hormônio de crescimento nos líquidos orgânicos, talvez porque a concentração dêle não seja suficiente para induzir uma resposta positiva nos animais hipofisectomizados. E possivel que a chamada hiperostose frontal interna também seja ocasionada por uma hiperfunção hipofisária, pelo menos transitória, e com reatividade particular do efetuador periférico. Não damos grande importância, para apreciação das hiperfunçôes hipofisárias, à medida da ação especifico-dinamica, porque o aumento desta não é de todo constante.

Uma produção maior do ou dos hormônios metabólicos na hipóíse só encontrou tradução até hoje nos diabéticos que acompanham o gigantismo ou a acromegalia. Talvez também algumas formas de diabetes insulino-resistentes encontrem sua explicação na existência de uma hiperfunção absoluta ou relativa da hipófise anterior.

$E$ de se notar que só os hormônios somatotrópicos e metabólicos da hipófise possuem uma ação geral sôbre o organismo, isto é, uma ação que se realiza sem a mediação necessária de outras glândulas de secreção interna.

Alterações da função lactogênica da hipófise se traduzem, quando há deficiència, por hipogalactia; quanto à hiperfunção, existem alguns casos raros de secreção láctea fora do período normal de lactação.

Uma alteração da função tireotrópica pode, algumas vezes, ser demonstrada no mixedema ou no bócio oxoftálmico, quando o teste de Aron ou a prova de Smelzer resultem positivas: neste caso, um extrato preparado da urina do paciente, determina a hiperplasia da tireoide do cobaio ou do pinto. 
Existe ainda um quadro de mixedema pituitário ocasionado por déficit de harmônio tireotrópico, e que só pode ser diferenciado do mixedema tireóidio, porque naquele a administração de tireoglobulina agrava os fenômenos orgânicos por acentuar a insuficiência supra-renal concomitante.

As deficiências da função gonadotrópica da hipófise, quando concomitantes a uma deficiência da função somatotrópica, originam o já citado nanismo hipofisário, e quando não acompanhadas por uma perturbação do crescimento, engendram o quadro da distrofia adiposogenital ou do eunucoidismo.

A etiologia hipofisária da primeira das afecções é indicada pelos três fatos seguintes: 1) a presença de obesidade, devida, não pròpriamente a um distúrbio da hipófise, mas a um distúrbio das regiões vizinhas do diencéfalo; 2) pelo achado, em algums casos, de alterações tumorais (tumor cromófobo da própria glândula pituitária); 3) pela reatividade efetiva desta áfecção ao tratamento com gonodotropina coriônica.

Já o eunucoidismo não se pode dizer se é sempre devido a uma alteração primária da hipófise ou da gônada: talvez a resposta ao tratamento ou a dosagem de gonadotropina na urina possam, em alguns casos, diminuir as dúvidas.

As alterações da função gonadotrópica que se processam na idade adulta em indivíduos até então normais, se caraterizam não mais por regressões morfológicas, mas por um abaixamento ou perda da função gonádica. Deve-se assinalar que todos os métodos de exame direto que demonstrem êste abaixamento da função não indicam, de per si, se o déficit é primitivo das gônadas ou da hipófise. Para esclarecer êste estado só dispomos da determinação da excreção urinária das gonadotropinas. Se o distúrbio fôr primitivo das gônadas, o teor de hormônio gonadotrópico na urina estará aumentado, caso contrário êle estará diminuído ou será nulo.

Poderá tambem servir de indício de origem hipofisária da afecção a simultaneidade de um outro distúrbio de natureza evidentemente hipofisária, como é o caso, por exemplo, das amenorréias que se instalam na acroinegalia ou estados acromegalóides. Não deve surpreender esta dificuldade de distinção etiológica em vista das relações recíprocas que prendem a hipófise e as gônadas entre si.

Da mesma forma as afecções que se caraterizam por inversão dos caracteres sexuais secundários, muito mais comuns na mulher do que no homem (voz grave, hirsutismo, hipertrofia do clitóris, etc.) são devidos au a um arrenoblastoma do ovário ou a um tumor ou simples hiperplasia da córtex supra-renal. Nesta última eventualidade é às vezes possível que a hiperplasia da córtex seja secundária a um adenoma basófilo da hipófise anterior (ou, pelo menos, a alterações citológicas) e assim nos defrontamos com a debatida questão de saber-se quando estas síndromes adrenogenitais são de origem córtico-supra-renal ou quando constituem a síndrome de Cushing. Há alguns dados sintomatológicos que, quando presentes (osteoporose, por exemplo) apontam a etiologia hipofisária e outros, como a hipertensão arterial, que, quando ausentes, põem-na em cheque, mas a verdade é que um método semiológico seguro para distinguir entre as duas possíveis causas não existe, mòrmente nos casos de caraterização incompleta. Em tese, terse-ia que pensar que a dosagem de hormônios gonadotrópicos pudesse auxiliar na diferenciação; entretanto, os dados até hoje acumulados a tal respeitc nada permite afirniar.

Os casos de puberdade precoce na mulher, quando não devidos a um tumor de células granulosas do ovário, são de origem hiporfisária.

Finalmente, uma insuficiència global de todas as funções da hipófise anterior acarreta o quadro da caquexia hipofisária ou doença de Simmonds, 
quase sempre muito difícil de ser diferenciada da anorexia nervosa. A não ser os casos em que aquela se instale após um parto, parece que a diferenciação terá que ser sempre obra do exame necroscópico.

$$
\text { Sessão extraordinária - 21, maŗ̧o, } 1944
$$

Lesão completa dos plexos lombar e sacro por seminoma. Drs. Oswaldo Lange, J. M. Taques Bittencourt e Romeu Cuócolo Sobrinho.

Este trabalho será publicado, na íntegra, no próximo número desta revista.

Patologia e terapêutica da ansizdade. Revista sumária do problema. Dr. Edmur de Aguiar Whitaker.

O A. faz considerações sumárias acerca da patologia e terapêutica da ansiedade. Esquematiza uma classificação das manifestações ansiosas baseada nas várias afecções ou estados mórbidos que a desencadeiam. Estuda o tratamento da ansiedade pelo hipossulfito de magnésio, referindo-se a numerosos casos que observou pessoalmente e em colaboração com Fausto Guerner. As conclusões, baseadas c.m cerca de 90 casos. são favoráveis; entretanto, precisa as indicações do hipossulfito de magnésio e mostra como seus efeitos parecem completar-se, em certos casos, com outras práticas terapeuticas. A conclusão final é de que, nos casos indicados, pára a remoção da ansiedade, o hipossulfito de magnésio figura como agente valioso, quer como adjuvante, quer como a principal terapêutica.

$O$ valor da reação de Steinfeld na paralisia geral progressiva. Drs. João Batista dos Reis e Ciríaco Amaral Filho.

Os AA., durante vários anos. estudaram o valor da reação de Steinfeld nos inalíticos gerais da Colônia "Franco da Rocha", secção de neurossífilis do Hospital de Juquerí. O número de casos estudados foi de 413, sendo que 260 eram agudos, isto é, pacientes que ainda não haviam sido submstidos a tratamento especializado, e os demais eram crônicos. Em muitos doentes observados foram colhidas diversas amostras de líquor, nos diversos períodos de evolução da moléstia, para se estudar as modificaçōes observdas no decurso terapêutico e tentar tirar uma dedução do valor prognóstico da referida reação. Apresentam, afinal: as seguintes conclusões: 1) a reação de Steinfeld mostra-se, nos casos agudos de paralisia geral e taboparalisia, positiva em elevada porcentagem (91\%); 11os casos crônicos, entretanto, esta positividade é muito menor (42\%), predomi1tando as reações negativas. 2) A dedução prognóstica, baseada na reação i!e Sieinfeld, ainda não está demonstrada de moło claro; entretanto, nosso estudo sugere que a negatividade da reação de Steinfeld em casos agudos de paralisia fueral oferece um prognóstico favorável enquanto a sua positividade persiste em exames seriados é indício de mau prognóstico. 3) A observação da diminuição cià intensidade da reação ou a sua negativação após tratamento não informa de modo evidente sôbre a melohria do quadro mental qu sofre evolução variada. 4) Estudando a influência do tratamento (malária ou quimioterapia) verificamos que, por vezes, há uma reativação, isto é, aumento de intensidade da reação, para depois decrescer; na maioria dos casos, a reação tende à negatividade após tratamento, havendo casos não influenciados em que a reação persiste positiva na dose de 1 c.c. de líquor. 5) $O$ estudo comparativo entre a evolução das reações de Steinfeld e de Wassermann, em exames seriados, demonstrou que a reação d? 
Steinfeld acompanha geralmente, com menos sensibilidade, a reação de Wassermann, sendo absoluta raridade demonstrar-se o fato contrário, isto é Steinfeld positiva em doses menores que a Wassermann. 6) Em relação à causa do óbito (icto, caquexia ou outras intercorrências clínicas) não verificamos uma predileção especial de incidencia dos resultados. 7) A maior incidência de resultados negativos da reação de Steinfeld, em casos agudos, sempre inclinou-se a favor das formas clínicas de prognóstico favorável.

\title{
Sessão ordinária - 13, abril, 1944
}

Psicanálise $e$ honorários médicos. Dr. Paulo Lentino.

Baseado em 21 observaçōes consignadas no registro de sua clínica particuar. o autor comenta os complexos de inferioridade que se instalam nos pacientes particulares nos quais o tratamento psicanalítico é feito gratuitamente, e as dificu!dades que daí decorrem para o médico.

Sôbre a leucotomia de Egas Moniz. Técnica e resultados. Dr. Antonio Carlos Barreto.

Este trabalho será publicado, na íntegra, no próximo número desta revista.

\section{CENTRO DE ESTUDOS FRANCO DA ROCHA}

\author{
Sessão ordinária - 21, janeiro, 1944 \\ PRESIDENTE: DR. FRANCISCO TANCREDI
}

Considerações a propósito de um caso de afasia (com apresentação do doente). Drs. Paulo Pinto Pupo e Mario Robortella.

Os AA. fazem, inicialmente, um apanhado geral sôbre o conceito atual das afas:as, começando com um retrospecto sôbre a integração normal da função ila linguagem e estudando a seguir os seus aspectos anatômico fisiológico e psicológico. Adotam a classificação das afasias em afasias de expressão e de compreensão, considerando aquêles distúrbios a.práxicos específicos para a linguagem articulada e eng:obando nestas os diversos tipos de afasias com perturbações do reconhecimento simbólico da linguagem e da própria linguagem interior. Reputam esta classificação bastante simples e de incontestável valor didático e clínico.

A seguir apresentam o paciente que, anteriormente à moléstia, foi de bom desenvolvimento intelectual e de regular cultura geral. Sempre foi homem de grande atividade em negócios, até que em setembro último foi acometido de um distúrbio circulatório encefálico que acarretou instalação progressiva de uma hemiplegia direita com predominância braquial, e de uma afasia total (de compreensão e de expressão). Além disso, distúrbios sensitivos no membro superior direito, distúrbios apráxicos frustos e hemianopsia lateral direita. Reações serológicas para lues fortemente positivas. $O$ exame do líquido cefalo-raquidiano revelou ligeira hipercitose e hipertensão de $35 \mathrm{~mm}$. (Claude), estando o doente sentado. $\mathrm{O}$ exame pneumoencefalográfico revelou dilatação assimétrica dos ventrículos 1a- 
terais, com predominância do ventrículo lateral esquerdo em sua porção parietoccipital. Diagnóstico: arterite luética com trombose de ramo cortical da silviana. Síndrome de lesão cortico-subcortical do lobo parietal esquerdo. A hemiplegia cedeu em 16 dias, permanecendo o distúrbio afásico.

Fizeram o estudo detalhado das perturbações da linguagem e instituiram o reaprendizado intensivo como terapêutica. Os fenomenos afásicos regrediram sensivelmente, apresentando o paciente, em novembro último, desordens acentuarlas da linguagem interior e da articulação das palavras, sendo que atualmente já consegue compreender em grande parte o que se lhe diz conseguindo também manter conversação, achando-se, entretanto, ainda perturbada a expressão verbal de modo acentuado. Alexia e agrafia persistem. Escreve séries inteiras de números e as lề, não conseguindo escrever números isolados, quando solicitado para isso, e nem mesmo ler números isolados. Os fenômenos de parafasia e jargonofasia são ainda relativamente numerosôs em sua expressão verbal. Ao lado disso, o paciente mantém íntegro o seu intelecto, possui todo o acervo dos conhecimentos adquiridos em sua vida, reconhece e avalia adequadamente o seu estado de afasia, está perfeitamente orientado no tempo e no meio e consegue andar sòzinho pelas ruas de S. Paulo, sem se perder ou se equivocar. Mantém hoa iniciativa e normal afetividade. $O$ indivíduo se comporta como pessoa normal em terra estrangeira - perdeu sòmente a capacidade de se comunicar com seus semelhantes por meio de símbolos da linguagem.

Afasia de tipo particular num paciente de "doença do Alzhcimer" (com apresentação do doente). Dr. Anibal Silveira.

Trata-se de um paciente de 62 anos de idade, internado no ano anterior $11^{n}$ Hospital de Juqueri. Não são conhecidos pormenores sôbre a história clínica vem os dados heredológicos, mas o comportamento objetivo e os sintomas clínicus são típicos da doença de Alzheimer. No quadro releva notar: 1) acentuaila carência de iniciativa, do tipo da do lobo frontal; satisfatória capacidade para avaliar a própria situação bem como para orientar-se em relação ao meio; ixpressão em geral extremamente perturbada - salvo quanto à mímica. 2) reações aietivas aparentemente sem alteração, apesar do aparente embotamento; normal capacidade de autocondução objetiva. O déficit de expressão constitui a nota principal do quadro, sendo mesmo eventualidade rara: consiste em agramatismo no sentido de perda de um elemento de prosódia - o substantivo. Daí resulta o recurso a perífrases, que se tornam intermináveis para o paciente, que não consegue vencer aquêle obstáculo na locução verbal. Os modismos de linguagem verbal e as expressões afetivas acham-se plenamente conservadas. Não se notam outros distúrbios focais, como agrafia intrínseca, alexia, apraxia motora ou ideomotora.

Nenhuma alteração do líquido cefalo-raquidiano no período atual. Foi feito o diagnóstico clínico de doença de Alzheimer, com lesões parietotemporais como primitivas, e frontais como secundárias, de repercussão.

\section{Sessão ordinária - 25, fevereiro, 1944}

Acidentes mecânicos da convulsoterapia. Drs. Celso Pereira da Silva e Paulo Ferreira de Barros.

Os AA. reunem todos os casos de acidentes mecânicos da convulsoterapia ocorridos no Hospital de Juqueri num período de 55 meses, isto é, desde maio de 938, época em que se registrou o primeiro caso de fratura, até dezembro de 
1942. Estudam apenas os casos que demandaram o concurso do serviço de radiologia para a sua elucidação, de modo que, na casuística apresentada, estão naturalmente excluídas as luxações simples, reduzidas pelo próprio médico assistente, sem necessidade do controle radiológico. Os dados estatísticos apresentados não têm um caráter de rigor absoluto, porquanto em algumas sessões do Hospital de Juqueri a terapêutica convulsivante não é feita de modo sistemático, faltando, pois, dados informativos exatos sôbre o número de doentes tratados. Em 1.843 pacientes submetidos aos tratamentos convulsivantes (cardiazol e eletrochoque) registraram os AA. os seguintes acidentes: 4 casos de fratura de coluna dorsal pós-cardiazol e 1 pós-eletrochoque; 1 caso de fratura do colo do femur pós-cardiazol; 3 casos de fraturas dos dois colos femurais pós-cardiazol; 1 caso de fratura do ramo horizontal do púbis póscardiazol; 2 casos de fratura do úmero pós-cardiazol; 1 caso de fratura do acrômio pós-eletrochoque; 1 caso de fratura da clavícula pós-cardizol; 1 caso de luxação da articulação escápulo-umeral pós-cardiazol. Em resumo, registraram 13 casos de acidentes ostearticulares pós-cardiazolterapia e 3 pós-eletrochoqueterapia. Nos casos observados, os AA. analisam os vários fatores que poderiam ser incriminados como responsáveis pelos acidentes: condições físicas dos pacientes, idade, doenças atuais e pregressas, estado do esqueleto, número de crises provocadas, outros tratamentos a que foram submetidos, quadros mentais observados. Estudam, a seguir, o mecanismo das fraturas constatadas, detendo-se particularmente nas fraturas da coluna vertebral. Passam ràpidamente em revista a bibliografia a respeito do assunto. Concluem, afirmando a desnecessidade da prática dos exames radiográficos prévios nos doentes tratados pelas terapêuticas de choque, como querem alguns autores americarios, sendo suficiente, via-de-regra, para prevenir eventuais fraturas, os os cuidados habituais tomados no decurso da crise convulsiva provocada.

\section{Sessão e.xtraordinária - 13, março, 1944}

Impressões de viagem aos Estados Unidos. Dr. Aloísio Mattos Pimenta.

Esta comunicação é a mesma feita à Seç̧ão de Neuro-psiquiatria da Associação Paulista de Medicina em 5 de fevereiro de 1944.

Sindrome digcstiva neuroanêmica. Considerações sôbre um caso. Dr. Ernani Borges Carneiro.

O A. passou em revista, prelimirarmente, os sintomas digestivos, neuropsíquicos e hematológicos encontrados na síndrome digestivo-neuro-anômica. Em seguida estudou um caso que teve ocasião de observar, em que o paciente mostrando um bom aspecto geral e não tendo qualquer sinal de anemia apresentava, no entanto, distúrbios para o lado da motricidade voluntária e sensibilidades superficial e profunda. Estabeleceu as várias possibilidades diagnósticas para chegar enfim, pelo exame do suco gástrico (prova da histamina) e hematológico, ao diagnóstico de síndrome digestivo-neuro-anémica, pois, além das manifestações nervosas apresentadas, o paciente em apreço era portador de uma anemia hipocrômica essencial com acloridria. Teceu comentários sôbre a etio-patogenia da afecção, para, em seguida, referir-se ao tratamento. Mostrou, por exames sucessivos, a melhora do paciente com um tratamento enérgico por vitamina $\mathrm{B} 1$, coadjuvada por $\mathrm{HCl}$ e Ferro. 


\section{Sessão ordinária - 22, março, 1944}

Psicoses psicógenas. A propósito de dois casos. Drs. André Teixeira Lima e Francisco Tancredi.

No primeiro caso, tratava-se de um sentenciado que, pouco após a prática de atos de libidinagem com duas filhas, mesmo antes da prisão, começou a apresentar alucinações auditivas com o caráter acusatório e imperatıvo, ao lado de fenómenos de automatismo motor, períodos de excitação psico-motora, tentativas de suicídio, etc., fenômenos èstes que se agravaram, após a prisão. Passada essa fase de auto-punição, o paciente, por mecanismo de projeção, compensação e refúgio, afastou-se da realidade, recalcando o delito e estabelecendo um quadro de pseudologia fantástica, na qual ainda se encontra mercê do que desapareceram os anteriores fenómenos, estabelecendo-se absoluta calma intrapsíquica. Apresenta ainda o paciente raros acessos convulsivos epileptiformes admitidos pelos AA. como de origem orgânica e por provável disposiçāo hereditária. $O$ segundo caso prende-se a um paciente jovem, com um quadro esquizofrênico, sem desagregação intelectual, apenas com distúrbios afetivos, em cuja história, bem apanhada por informes seus e de terceiros, pôde ser assinalada a existência de traumas afetivos, ocorridos na infância e puberdade, criando uma série de recalques e sintomas neuróticos graves. Posteriormente, com o casamento, estabeleceu-se uma coitofobia, surgindo dai por diante os fenómnos psicósicos, rotulados como reação esquizomorfa.

\section{Sessão extraordinária - 27, março, 1944}

Anguistia - ação psicógena sôbre o hipotálamo. Prof. Flamínio Vidal (docente da Universidade de Buenos Aires). Conferência.

Lembrou inicialmente a divisão corrente do sistema nervoso, nos estágios superiores da escala zoológica, em sistema de relação e sistema neurovegetativo. Na realidade, a divisão é ternária, com a distinção dêste último em sistema defensivo (simpático) e sistema nutritivo (parassimpático). Aludiu aos mecanismos neuronais que põem êsses sistema em contacto com as vísceras: num caso, centralização em cadeias ganglionares, acessíveis inclusive à extirpação; noutro, difusão em terminações intraviscerais. Caraterísticas comuns em ambos os casos são a regência funcional estabelecida por núcleos hipotalâmicos, e a transmissão do influxo nervoso mediante agente bioquímico, num caso a acetilcolina, noutro a adrenalina. Por outro lado a atuaç̃o dos sistemas defensivo e nutritivo se faz sentir, na zona terminal, no calibre dos vasos capilares, cujo endotélio funciona como elemento ativo, além da atuação como membrana semipermeável. Daí resulta, em última análise, que, pelo estímulo nervoso, pode ocorrer a alteração do equilíbrio osmótico no líquido intersticial que medeia entre o capilar e o sistema celular circunjacente. Este desequilíbrio osmótico a seu turno vai modificar o quimismo intracelular e, assim, provoca outras reações na bioquímica do sangue. Estes distúrbios, em seguida, poderão atuar sôbre o funcionamento das células nervosas do encéfalo, as quais podem, assim, sofrer os transtornos diretos já referidos por embebição ou edema. Daí a importância do exame bioquímico do sangue nos casos de doenças mentais. Entretanto - e aí está o tema principal da conferencia - as funções reguladoras do hipotálamo podem ser intensamente estimuladas por mecanismos puramente psíquicos, como o evidencia a clínica e como o demonstram as experimentações em animais de laboratório. Descreveu experièncias concludentes nesse sentido, chamando novamente a atenção para as desordens bioquímicas do sangue provocadas por essa ação psíquica. 